\title{
MORTE VOLUNTÁRIA ENTRE \\ A JUVENTUDE KAIOWÁ
}

\author{
Raphael Gouvêa Rompinelli ${ }^{1}$
}

\section{RESUMO}

O presente trabalho tem como objetivo uma abordagem introdutória ao tema do suicídio kaiowá. $\bigcirc$ artigo inicia-se situando historicamente a presença destes no Mato Grosso do Sul, Brasil, e apresentando aspectos fundamentais da vida social deste povo indígena, particularmente no que diz respeito à sua relação com a terra. Em seguida, comenta brevemente um tratamento clássico do suicídio nas Ciências Sociais e um importante estudo sobre suicídio na Etnologia Sulamericana, para passar à consideração das especificidades do suicídio kaiowá. Identificado como prática adotada predominantemente por jovens, o suicídio parece estar ligado a temas chave do parentesco, da construção da pessoa e da sociabilidade, como: a ausência de parentes; a feitiçaria e vingança; a passagem à vida adulta. Por fim, o trabalho chama atenção para a dimensão da "juventude kaiowá" e sua presença política atual, sugerindo uma possível abordagem do suicídio a partir dos próprios discursos/falas juvenis.

Palavras-chave: Kaiowá, juventude, suicídio, ciências sociais.

${ }^{1}$ Graduando do curso de Licenciatura em Ciências Sociais da Universidade Federal de Juiz de Fora. Bacharel Interdisciplinar em Ciências Humanas e Bacharel em Ciências Sociais pela Universidade Federal de Juiz de Fora. Contato: raphaelrompinelli@yahoo.com.br 


\section{INTRODUÇÃO}

Atualmente o território brasileiro possui uma população indígena aproximada de 896, 9 mil pessoas, distribuídas de maneira não homogênea por toda extensão nacional. Destes, um total de 36,2\% vivem em áreas urbanas e 63,8\% em áreas rurais, em aproximadamente 505 terras indígenas demarcadas ou não, ou estão dispersos em núcleos provisórios de habitação. A segunda maior população à etnia Guarani Kaiowá com aproximadamente 43.401 mil pessoas, sendo o maior contingente Tíkuna, com 46.045 mil habitantes (IBGE, Censo 2010).

Os Guaranisãoconhecidos porváriasnomenclaturas: Chiripá, Kainguá, Monteses, Baticola, Apyteré, Tembekuá, dentre outros. Todavia, estes se autodenominam e se designam como: Avá, que dentre outros termos significa, "pessoa", o ser Guarani.

Pertencentes ao tronco linguístico Tupi, os Guarani-Kaiowáhabitam suas terras historicamente divididos em grupos familiares extensos, chamados de te'y, estes por sua vez são assentados em agrupamentos macro familiares denominados de tekoha. Cada um destes possui dentro de seu grupo certa liberdade, no que se refere à escolha dos casamentos, na orientação dos jovens e divisão do trabalho. Existe no Brasil aproximadamente 85 áreas exclusivas aos Guarani, que são dispersas principalmente na região sul do país e no estado de Mato Grosso do Sul. Fora do território nacional, no Paraguai, parte na Bolívia, Uruguai e Argentina encontram-se, também, diversos subgrupos guarani. Em nosso país é reconhecida a presença de três subgrupos: Mbya, Nhandeva e Kaiowá, sendo estes últimos, o objeto deste Projeto.

Sobre os guaranis Kaiowá notamos também que estes ocupam o segundo lugar em habitantes por terras indígenas, com aproximadamente 35.276 pessoas vivendo em zonas próprias, e ficam na terceira posição em relação à população fora das terras indígenas com o número de 8.125 mil pessoas, ficando atrás dos Terenas com 9.626 mil pessoas e os Baré com 9.016 mil pessoas fora de uma zona própria de habitação (IBGE, Censo 2010).

Os Kaiowá são conhecidos, atualmente, na mídia brasileira - e também internacional - principalmente pelas situações de conflito com fazendeiros e os defensores dos interesses do agronegócio no Mato Grosso do Sul. Como demonstrarão os dados adiante, a situação de suas terras tornou-se um problema crônico que se desdobra frequentemente em extrema violência contra os índios. Ainda, nas últimas décadas, um evento que chamou a atenção da sociedade brasileira - principalmente nos anos 1990 - foi o alto índice de suicídios entre 
jovens kaiowá, tema do qual se ocupará este trabalho.

A taxa de mortalidade que se apresenta nesta etnia e a porcentagem de mortes provocadas voluntariamente, que espanta pelo volume e modus operandi. Brand (1997) demonstra, através de um apanhado de dados o número de suicídios de 1981 até 1996, somando um total de 281 casos ao todo nesses 15 anos, sendo os maiores números registrados nos anos de 1990 com 38 casos registrados, em seguida o ano de 1994 com uma leve queda, mas ainda sim com 33 ocorrências e com um grande aumento o ano de 1995 com o número de 56 casos.

Os dados recentes comprovam que ainda é grande o número de casos. Assim, o relatório divulgado pelo CIMI (Conselho Indigenista Missionário), Violência contra povos indígenas no Brasil - dados de 2015, demonstra a alarmante realidade em que vivem os Kaiowá. Em 2000 o número chega a 44 casos em 2005 atinge 55 ocorrências em 2010, com uma queda, chega aos 40 e em 2015 com um crescimento, o número de suicídios chega a 45.

Nota-se o quanto esses dados são expressivos e conforme veremos adiante com maiores detalhes, eles atingem uma faixa específica da população, principalmente os jovens e recém-casados, em um intervalo etário de 15 até 24 anos. Creio que o contato com estas cifras foi determinante para a escolha do tema a ser trabalhado neste artigo de conclusão de curso.

Para este texto, foi realizado pesquisa bibliográfica envolvendo tanto a leitura de etnografias sobre os Guarani Kaiowá quanto de artigos e textos acadêmicos em geral voltados para a análise do suicídio. As etnografias, acessadas principalmente a partir de bancos de teses no Brasil, permitiram uma abordagem mais ampla do modo de vida e de processos históricos vividos pelos Kaiowá, e, em alguns casos, tematizam diretamente o suicídio. $\bigcirc$ artigo pretende construir um panorama sobre o suicídio entre jovens kaiowá, trazendo as diversas argumentações ou tentativas de compreensão deste fenômeno e apontando, ao final, caminhos alternativos possíveis de reflexão sobre práticas adotadas por jovens indígenas, como as novas formas de expressão e participação política.

\section{O SUICÍDIO NAS CIÊNCIAS SOCIAIS E ENTRE OS AMERÍNDIOS: UMA PRIMEIRA APROXIMAÇÃO}

No campo científico, conforme apresenta Giddens (2001), o tema do suicídio já era assunto de debate na França e em outros países desde o século XVIII, preocupados em sua maioria com aspectos morais sobre tal tema, foi somente 
no início do século XIX que bases estatísticas surgiram para analisar o fenômeno pela Europa.

Uma das primeiras pesquisas sistemáticas foi elaborada em 1822 por Falret, intitulada; Da hipocondria e do suicídio. Falret, como colocado por Giddens (2001) faz uma análise profunda das causas internas, os transtornos mentais hereditários resultadas nas tendências suicidas dos indivíduos como das causas externas, que eram responsáveis pelas variações nas taxas de suicídios entre diferentes grupos. Após o trabalho deste autor, inúmeros outras análises foram surgindo ao passar dos anos, principalmente entre franceses, alemães e italianos.

Durante os anos iniciais do século XIX, surgiram trabalhos que destacaram a discrepância entre os números de casos que ocorreram em zonas urbanas se comparadas a áreas rurais, a diferença entre determinados períodos do ano, relacionado a grupos religiosos como também fatores raciais e climáticos.

A maior parte dos trabalhos que foram elaborados no início desse século possuía, de acordo com Giddens (2001), uma estreita relação entre a justificativa dos atos suicidógenos e problemas mentais. Uma insanidade que teria suas bases em uma inspiração diabólica, ainda sob influência da igreja, que fora predominante no século XVIII e que ainda deixava marcas na primeira metade do centenário seguinte.

Durkheim, sem dúvida não foi o primeiro, dentro das ciências sociais a discutir sobre o fenômeno do suicídio, tão pouco foi o primeiro a se dedicar ao binômio explicativo dividido entre indivíduo e sociedade, ou transtorno mental ou o mau funcionamento social, todavia:

\begin{abstract}
Aspecto em que o trabalho durkheimiano diferiu decisivamente foi à tentativa de explicar as descobertas anteriores em termos de uma teoria sociológica coerente. Os escritores que o precederam haviam utilizado uma metodologia estatística global para demonstrar as relações entre as taxas de suicídio e vários fatores: Durkheim desenvolveu essa técnica para respaldar uma explicação sociológica sistemática das taxas diferenciais do suicídio.
\end{abstract} (GIDDENS, 2001, p. 232).

A partir do desenvolvimento de seu método sociológico, tal autor propõe uma compreensão de um fenômeno que fora simplificado por reduções em suas particularidades ou entendido como associado a disfunções individuais. A compreensão do fato social é de essencial valor na teoria durkheimiana, 
transpondo a noção do suicídio puramente individual e vinculando as causas e motivos sociais, articulados à teoria da anomia proposta pelo autor.

O autor estabelece que o suicídio possua causas sociais e estas devem ser levadas em consideração ao se construir tipologias para tentar compreender o ato em si. Dessa forma, Durkheim (1987) estabelece uma tipologia como forma de interpretação e constrói três principais classificações como formas fundamentais para explicar as atitudes suicidógenas.

Analisando perspectivas que ressaltam a vida religiosa e familiar, elencando famílias com filhos ou não, grupos religiosos como católicos protestantes e judeus o autor francês propõe uma série de fatores que podem impelir o sujeito a cometer o suicídio, cada qual com sua especificidade. Os católicos são menos livres na escolha de suas ações e por sua vez seriam mais sujeitos aos ditames coletivos, assim sendo mais integrados à sua comunidade. Os protestantes possuem maior liberdade de escolha e por ser assim é compreendido com maior parcela de responsabilidade pelos atos cometidos. Já os Judeus teriam uma possibilidade de escolha muito menor, estando diretamente ligados às regras impostas pelas tradições e as normas do grupo.

Uma das categorias por ele proposta coloca maior peso na perspectiva individual em comparação com o grupo social ao qual o indivíduo está inserido e por representar uma ruptura, por parte da excessiva individualização, em relação ao grupo, esta é denominada pelo autor de suicídio egoísta.

Contraponto a essa, Durkheim (1987) constrói outra, o suicídio altruísta. Se o excesso de individualismo pode impelir o indivíduo à morte auto infligida, a falta deste poderia ter respostas semelhantes. Em forma e reconhecimento um gesto impessoal em grande medida devido ao forte teor de integração do indivíduo ao grupo, devido ao mínimo valor deste último em comparação a importância quase absoluta da coletividade ao qual o indivíduo está inserido.

Por fim, se compreende uma última categoria, que é representativa do estado de desregramento, sérias mudanças no tecido social, um estado de desagregação social responsável por súbitas mudanças da vida em comunidade. Estes aspectos que causam uma forte mudança repentina da vida social produzem uma forma de autoagressão muito particular denominada por Durkheim como suicídio anômico. Por fim em uma nota de rodapé este autor ainda caracteriza outra forma de suicídio, já demonstrando ressalvas devido a sua não existência em seu tempo, o suicídio fatalista; que pode se colocar em uma situação oposta a anomia, uma forma de morte auto infligida típica de escravos que submetidos a um excesso de 
regulamentação e opressiva não encontrava outra escapatória e se matava.

Ainda sobre este tema, Jeffreys (1952, apud Dal Poz, 2000, p. 25), desenvolve um conceito, a partir de sua pesquisa na África, designado como suicídio sansônico, uma forma de vingança. Este se consiste no fato de o sujeito procurar uma retaliação a quem Ihe cometeu algum agravo, ou na condição de um fantasma, ou na aplicação de sanções contra quem Ihe cometeu algum dano.

Dando continuidade à perspectiva Durkheimiana, em 1930, Halbwachs publica um trabalho em que analisa a luz de métodos estatísticos contemporâneos às conclusões que chegou Durkheim 30 anos antes. Giddens (2001) concorda que em linhas gerais a análise de Halbawachs confirma em vários pontos a perspectiva de seu predecessor, contudo ele contesta a tipologia do suicídio egoísta e anômico. Este autor alega que diferente da forma de análise de Durkheim, é incorreto utilizar relações estatísticas de forma independente; meio familiar, grupos religiosos, etc. Tais categorias não podem ser consideradas de maneira separada e como se fossem independentes de um contexto muito mais amplo.

Dentro da etnologia sul-americana, o tema foi debatido por Dal Poz (2000) considerando o contexto dos Suruwaha, povo de língua Arawa. Desde a década de 1980 até 1995 houve uma contabilidade de trinta e oito suicídios cometidos pelos Sorowaha, sendo um total de dezoito homens e vinte mulheres em uma população média de 123,6 pessoas em uma projeção aritmética de 1.922 casos de suicídio para 100 mil habitantes, associados a diversos motivos, desde a briga no contexto familiar até o furto de pequenos objetos etc.

O suicídio Sorowaha é uma prática social ritualizada, envolvendo o grupo familiar extenso e uma série de atitudes socialmente orientadas. O autor desenvolve o que é denominado de Script comportamental, uma sequência de atitudes que se inicia por um confronto do sujeito com os mais amplos fatores e culmina em sua morte. Inicialmente este se declara irritadiço para um ente próximo; em seguida, em uma atitude de fúria, destrói todos os seus pertences, ato que não é impedido pelos seus próximos. Dando continuidade a essa atitude, o sujeito se lança à procura da raiz de timbó, veneno muito utilizado por essa etnia. Percebendo isso um grupo de amigos ou familiares vai à busca deste para impedi-lo. Caso a busca seja bem sucedida, o parente é salvo; caso não, este ingere o veneno e tenta voltar para sua casa para perecer perto daqueles com quem viveu (Dal Poz, 2000).

A análise de Dal Poz vai de encontro à teoria durkheimiana, demostrando que, para o caso Suruwaha, não é possível compreender o suicídio nos termos da 
relação indivíduo - sociedade e através da noção de anomia. Reconhecendo o suicídio como prática dotada de sentido compartilhado socialmente, é preciso perseguir, através da etnografia, os significados e emoções que se fazem presentes nestes momentos tal como experimentados pelos sujeitos indígenas envolvidos.

Dal Poz (2000) defende que o caso entre os Suruwaha, apresenta-se de tal modo que permite questionar um postulado que é dado com naturalidade, o de que o suicídio é um representante do índice de infelicidade, o insucesso do indivíduo e a derrota da sociedade. Desta forma, conforme argumenta o autor, não é possível compreender o suicídio como fato social e deduzi-lo como um resultado indesejado do funcionamento anômico da sociedade.

A partir desta breve exposição, entendemos que uma análise do fenômeno da morte voluntária entre os indígenas deve explorar o contexto dos estados emocionais que não se desvincula ao que parece do campo do parentesco, estruturante na vida das sociedades indígenas de modo geral.

No contexto kaiowá, observo o modus operandi das mortes que os jovens têm experimentado. O suicídio é um ato privado, realizado às escondidas e em um local afastado. Muitas vezes é precedido de um estado de embriagamento para se tomar coragem e em grande número de casos é precedido ainda por uma ameaça ou insinuação, muitas vezes após brigas familiares ou conjugais.

No campo das emoções, dois estados distintos que se atualizam nas pessoas parecem estar associados às ações dos suicidas: o vy'ae'y e o nhemyrõ. O primeiro deles compreende uma ausência da vontade de viver; a falta de "alegria" falta de gosto pela vida. $O$ segundo termo diz respeito a uma situação de obstáculo nunca ultrapassado, impeditivo da realização de um desejo, que produziria um misto de braveza, desespero e tristeza que abate a pessoa, como argumenta Pimentel (2007).

Estes estados emocionais seriam principalmente perigosos para os sujeitos em fase de transição da infância para a vida adulta, isto tanto para rapazes quanto para moças. Estes períodos são marcados pela mudança de voz para os homens e pela menarca (primeiro mênstruo) para as mulheres. Durante essa fase os jovens são especialmente suscetíveis a se tornarem nhemyrõ.

Entre os Guarani Kaiowá existe essa instabilidade emotiva que pode acompanhar a passagem da puberdade para a vida adulta, então é necessário atenção ao se lidar com os jovens. Porque pode ser despertada uma cólera que existe de maneira latente e que deve ser controlada. Por outro lado, partindo 
da perspectiva dos jovens, há uma dificuldade em aceitar certas restrições comportamentais implicadas nos períodos de resguardos, isso somado a dificuldades conjugais, os tornaria possivelmente mais suscetíveis ao suicídio devido as grandes cargas emocionais.

Dentre as hipóteses apresentadas na bibliografia sobre o suicídio entre os Guarani-Kaiowá, pode-se destacar segundo Costa Pereira (1995 apud Pimentel, 2006, p. 65-66), o alcoolismo, feitiçaria, situação econômica precária, multiplicação de grupos evangélicos, a busca pela "terra sem males". Podemos acrescentar ainda o ethos minimalista e o complexo do guerreiro antropofágico (LEVCOVITZ, 1999), o histórico conflito de terras em áreas indígenas (BRAND, 1994), dentre inúmeros outros. Todavia a etnologia Kaiowá contemporânea demonstra que a dinâmica social Guarani- Kaiowá se mantém operante, de modo que não me parece que sejam plenamente satisfatórias as teses que explicam o suicídio kaiowá unicamente pela "desestruturação social" ou por outras negativas. Pelo contrário, meu interesse de aproximação com o tema do suicídio vai à direção de considerá-lo junto com outras formas de agir dos jovens kaiowá. Penso que pode ser interessante relacioná-lo com o desenvolvimento de práticas de atuação características entre jovens, envolvendo formas particulares de discursos e defesa dos interesses, como ocorre em expressões musicais adotadas recentemente.

Antes de uma abordagem direta do suicídio conforme estas perspectivas demonstram, apresentaremos a seguir, aspectos fundamentais do modo de vida Kaiowá e da cosmologia, assim como são descritos na literatura clássica sobre o grupo.

\section{OS KAIOWÁ, A TERRA E DIFERENTES MODOS DE VIVER NELA: CONCEITOS NATIVOS E PROCESSOS HISTÓRICOS.}

A contar da segunda metade do século XIX a ocupação no território do Mato Grosso do Sul se deu em várias frentes de avanço e por consequência o contato com os Guarani que naquela região estavam dispersos. Esta ocupação se intensificou em meados de 1861 com a instalação da Colônia Militar de Dourados próximo à cidade de Ponta Porã. Em segunda instância, mas não menos relevante, o término da Guerra do Paraguai no ano de 1870 provocou uma dispersão de ex-combatentes, incluindo Paraguaios, por toda aquela região que se empregaram como mão de obra da Cia de Matte Laranjeiras ou em fazendas 
de Gado que foram retomadas ao término da Guerra. Esta empresa possuía uma influência econômica que alcançava toda região sul do estado do Mato Grosso do Sul, empregando mão de obra paraguaia, de brasileiros e também de Kaiowá e de outras populações Guarani que habitavam aquele espaço territorial. (CimiMs et al, 2000).

Já no século XX, em 1941 com a criação da Colônia Agrícola Nacional de Dourados (CAN), empreendida dentro do período de incentivo pelo Governo de Getúlio Vargas e pela política de expansão para a região oeste do país. Este cometimento afetou de maneira direta uma série de tekoha dos Kaiowá, mas principalmente os dos entorno dos rios Brilhante, Santa Maria e Laranja Doce.

Com o fim da Cia de Matte Laranjeiras e o período de "Marcha para Oeste", no final dos anos 1950 se intensifica a exploração das matas e a instalação de fazendas; uma atividade que atingiu fortemente os Kaiowá. Assim dá-se o início de um movimento que se denominou "esparramo" e que além de significar a perda de terra para os fazendeiros, foi através deste movimento que se inicia a dispersão dos grupos familiares e o desmantelamento das famílias extensas. A expansão do agronegócio teve e ainda tem grande influência sobre a organização desses grupos; interfere fortemente no ambiente, atua nos deslocamentos, ou impondo ou proibindo, mas, sobretudo submete os Kaiowá a uma forma de controle e desarticulação nunca antes vivenciada, como defende Pimentel (2006).

O período de colonização que se estendeu durante os anos 1950 e 1970 intensificaram o modo de produção baseado no latifúndio e que se estabeleceu de tal modo que impossibilitou a convivência entre a grande propriedade e a exploração da terra para a subsistência dos pequenos grupos indígenas. No decorrer dos anos 1980, o trabalho indígena era apreciado pelos colonos, o que gerou um fenômeno de confinamento das famílias que serviam como trabalhadores e favoreceu sua concentração em determinados espaços que outrora não eram ocupados por estes grupos:

Passado o auge das atividades de derrubada da mata que se estendeu pelas décadas de 1960 e 1970 a mão de obra indígena foi canalizada para a roçada dos pastos e para o plantio das pastagens exóticas. E, finalmente durante a década de 1980, passou a ser mão de obra preferida para os trabalhos de plantio e colheita da cana nas usinas de álcool. As atividades nas usinas de álcool absorvem a quase totalidade da mão de obra indígena, ao contrário do desmatamento e da limpeza dos pastos que se caracterizou pelo esparramo, 
exigiu confinamento e sua concentração. (Brand, 1997; p. 90)

A "changa", como ficou caracterizada; um trabalho temporário que era realizado pelos indígenas por determinado tempo. Sofreu uma modificação e abriu espaço para o trabalhador assalariado e continuado por até 10 meses, geralmente durante os períodos referentes ao plantio, manutenção e colheita da cana de açúcar e o seu processo final nas usinas de produção de álcool. Esta forma de trabalho conforme defende Brand (1997) foi responsável por um assalariamento compulsório devido à escassez de outros modos de subsistência dentro das reservas. Isso demonstra, segundo o autor, que tanto o movimento de esparramo e logo em seguida o de confinamento, teve como razão principal os motivos de ordem econômica, o que poderia confirmar a submissão das políticas indigenistas perante os interesses maiores da exploração agrícola e por consequência fenômenos econômicos regionais.

Com o fim deste processo de "mistura" e posterior confinamento destes grupos próximos às fazendas, estas foram tomadas pelo aldeamento compulsório, tanto os Kaiowá quantos os outros Guarani foram para as oito reservas demarcadas na época e neste processo não foi observado, ou sequer considerados os grupos ou famílias extensas (te'yi) nem o modo de ser daqueles grupos, juntando assim, núcleos familiares que não possuíam nenhum grau de parentesco e separando outros que o possuíam. Desta forma ao mesmo tempo em que se viam longe daqueles com quem tinham laços tradicionais se viram confinados com outros grupos que possuíam pouco ou o mínimo contato, de acordo com Pimentel (2006).

A política do aldeamento promovida na área habitada pelos guaranis consistia, assim, basicamente em remover a população dispersa em núcleos esparsos e agrupá-las de maneira tutelada pelo Estado e por órgão específicos como o Serviço de Proteção ao Índio (SPI). Conforme salienta Brand (1997), essa era a fórmula que se usava para a criação de espaços vazios em uma região densamente ocupada por grupos Guarani de forma geral, abrindo espaço para o surgimento de novas áreas de exploração.

Foram graves as consequências que estes fenômenos criaram no modo de vida desses grupos afetados, indicando total provisoriedade das famílias após serem removidas e movidas de seus tekoha tradicionais. A importância desta instância para os Kaiowá/Guarani é de fundamental interesse para a compreensão neste breve estudo. A caracterização como um simples lugar de habitação, para os 
Guarani não parece ser suficiente. Esta é uma esfera de compreensão que merece ser mais bem detalhada aqui.

Trata-se da conceituação e compreensão da terra em um sentido que extrapola o bem físico e material, e que está presente na noção de tekoha; que é o lugar onde vivem segundo seus costumes, é a comunidade, local de percepção do ser, onde a realização da pessoa guarani é possível. Este espaço é dado de tal maneira que Meliá et al. (1976) alegam que, apesar de seu tamanho pode variar conforme a superfície ocupada, o local e a situação e quantidade de famílias, a estrutura e a função se mantém igual em importância e real na ação. Possui liderança religiosa e política e forte coesão social. No tekoha são realizadas as principais festas e as decisões políticas e formais nas reuniões gerais. É sobretudo uma instituição divina criada por Nhande Ru.

Sobre este ponto é necessário uma explicação para que possamos continuar. Nhande Ru é reconhecido como a maior divindade para os Guarani. Mas principalmente sobre o aspecto aqui abordado, Nhande $R u$ foi quem se encarregou da organização da terra, segundo Meliá et al. (1976), este veio de Yvypyte (uma região situada entre a terra onde habitamos e o paraíso), mas foi Nhande Ru quem criou as grandes montanhas e estabeleceu os tekoha, também criou alguns animais como as minhocas, as cobras e os escorpiões.

Todavia o tekoha extrapola a função que podemos compreender com o termo localidade ou comunidade ou espaço físico; possui também outras dimensões extra espaciais, que demonstram a complexidade deste termo e a importância do mesmo dentro da vida dos Guarani. Conforme argumenta Meliá et al. (1976), essa esfera possui uma importância moral e é responsável pelo bem estar e social. O que permite um alargamento do termo de tal forma que não possuímos uma palavra específica para isso e o problema da tradução, como território ou comunidade é demasiado simplista. O local que fora dado por Nhande Ru deve ser habitado e cuidado, as tradições devem ser mantidas, praticadas e perpetuadas, não é simplesmente um lugar em que estes habitam ou moram, possui um significado mais amplo, o que permite aos Kaiowá uma auto identificação com a terra.

Sem a materialidade da terra não há possibilidade de se tornar um ser socialmente existente e compreendido dentro de um grupo cultural, e que pode ser resumida na frase de Meliá et al. (1976) sem tekoha não há teko ("modo de ser", "maneira de ser" Guarani). Nesta perspectiva, a terra não é um objeto a ser possuído ou a ser utilizado de forma intensiva, pois é o espaço que possibilita o 
tornar-se humano, o viver (bem) (-iko porã) entre parentes.

\section{SUICÍDIO DE JOVENS KAIOWÁ}

Como observa Pimentel (2006), o suicídio entre os Guarani Kaiowá do Mato Grosso do Sul começa a ser reconhecido como um fenômeno social no final dos anos de 1980, quando os seus números de ocorrências deram um salto, segundo o autor, de uma média de 5 a 8 casos por ano para 38 mortes em 1990, sendo que a partir deste ano, os números não se mantiveram em uma faixa inferior a 20 casos anuais. No período que compreende os anos 1996 até 1998 os casos se estabilizaram em torno 30 ocorrências, para que no ano de 1999 o número chegue à faixa dos 50 casos. Podemos perceber que este é um aumento expressivo para uma população que em 2005 somava 35 mil pessoas.

Até 1998 os casos eram registrados e atualizados pela própria FUNAI (Fundação Nacional do Índio) e pelo CIMI (Conselho indigenista Missionário). Mas desde 1999 a FUNASA (Fundação Nacional de Saúde) tem se encarregado de atualizar os números, sendo relativamente fácil de encontrar os dados sobre o suicídio entre os Kaiowá. Conforme situa Brand \& Vietta (2001), em um levantamento mais abrangente de 1981 a 2000 houve 436 casos, principalmente concentrados na região de Dourados.

Dados mais recentes estão disponíveis para a visualização e são de livre acesso em um Relatório de Gestão 2010 publicado pela FUNASA (2011), havendo uma tabela que coloca as taxas de mortalidade por suicídio (X 100.000) por sexo e por ano, a qual demonstra a atualidade destes casos, construindo um panorama de morte auto infligida entre os Guarani Kaiowá e Nhandéva no Mato Grosso do Sul em um intervalo de tempo que se estende de 2000 até 2009. Nele podemos observar claramente a evolução do número. No ano de 2000 somam 90 ocorrências, sendo que no ano 2002 é o mais expressivo destes números no que toca ao número de mortes, superior a 100; a partir desta data, tem-se uma queda e em 2008 a contagem volta a crescer para 90 acontecimentos, finalizando os dados disponíveis em 2009 com 64 eventos de suicídio.

Podemos trabalhar com dados ainda mais recentes, em Relatório publicado pelo CIMI intitulado "Violência Contra os Povos Indígenas no Brasil: dados de 2015", coordenado por Lúcia Helena Rangel. O relatório reúne dados que se estendem de 2000 a 2015, tendo como foco o número de casos ocorrentes no estado do Mato Grosso do Sul. Se considerarmos esse intervalo de 15 anos, 
foram 752 ocorrências registradas, tendo como maior pico os anos de 2008, conforme já apresentado anteriormente e o ano de 2013 com 73 casos, sendo que os anos de 2014 e 2015 registraram uma queda, respectivamente 48 e 45 registros.

Outro fator que podemos extrair deste relatório é a concentração do suicídio em uma faixa etária específica, isto é, de pessoas com até os 29 anos, sendo que as maiores incidências são de jovens de 15 a 29 anos com um somatório de 37\% do número de ocorrências. Para além dos dados, esta concentração é observada em estudos como os de Brand \& Vietta (2001) como fator relevante ao se estudar o suicídio entre os grupos Kaiowá. De acordo com Pimentel (2007) podemos compreender que o número de mortes auto infligidas possui uma concentração em um perfil etário entre jovens adultos e outra no que se refere ao gênero, o masculino.

Como foi dito anteriormente, existe uma percepção entre os grupos Guarani sobre o perigo em relação à instabilidade emocional que segue durante a puberdade, os jovens estando mais suscetíveis a desestabilidades emocionais. É necessário, conforme indica Pimentel (2006), que se tenha cuidado na forma como se fala com os jovens, não se devendo ser muito duro e ríspido.

Neste período, o adolescente tem uma grande chance de ficar nhemyrõ. Pimentel (2006) apresenta esse termo como um obstáculo existente para a realização de um desejo imediato. $O$ estado de nhemyrõ consiste em um misto de braveza, melancolia e desespero que abate a pessoa e pode levá-la ao suicídio. Esse estado possui uma chance maior de se constituir durante o período da adolescência e durante os primeiros anos de casamento.

Outro estado que é trabalhado por Pimentel (2006) e o vy'aéy; uma ausência de vontade de viver, um descontentamento com a vida. Pode ser manifestado em determinada situação em que a pessoa, tendo um obstáculo aparente, ou um problema cotidiano e não se sentindo capaz de superá-lo se torna vy'ae'y. Este estado pode levar a pessoa a cometer o suicídio.

Existem estados psicológicos bem específicos daqueles que retiram a própria vida, mas podemos argumentar aqui também que existe uma forma ou uma particularidade específica na performance dos atos, ou seja, como os suicídios são cometidos. Conforme segue Pimentel (2006), pode-se encontrar nas estatísticas uma constante no que toca a forma como o ato é cometido. O enforcamento é na maioria dos casos a maneira escolhida pelos Guarani e Kaiowá, e, em menor quantidade, a ingestão de venenos. Dos 436 casos citados por Brand \& Vietta 
(2011) no intervalo de ano de 1981 a 2000, 340 foram por enforcamento, o que corresponde a 77, 98\% do total.

Osuicídio Kaiowáé ressaltado por este autor Brand e Vietta (2001) como sendo, na maioria dos casos, um ato privado, realizado longe dos olhares daqueles com quem se têm relações, longe dos amigos e, sobretudo longe da família. Executado de maneira furtiva, em geral é um ato silencioso e por isso mesmo é de difícil detecção. A pessoa, antes do ato, desaparece, planeja de forma secreta e vai até um local isolado ou espera que não tenha ninguém próximo para assim acometer contra si mesmo. Em algumas situações o ato em si é precedido de embriaguez.

Poucos são os indícios que são deixados pelo suicida Guarani e Kaiowá que evidenciem sua intenção de se matar. Em algumas situações, o suicídio pode ser precedido de uma briga familiar, ou mais ainda, pode vir após uma desavença conjugal seguida de uma ameaça de abandono familiar e na sequência cometer o ato. Em outras vezes, é acompanhado de uma mudança de temperamento repentina ou evasão do contexto familiar.

O ato chama a atenção, pela grande vontade pela qual é acometida e possui uma característica em particular. Em inúmeros casos, segundo Pimentel (2006), o local onde se prende a corda é um local baixo, menor do que o tamanho de uma pessoa estendida sobre os pés, ou seja, o suicida costuma proceder em sua ação final, de joelhos no chão, enquanto se amarra por meio de uma corda, suas próprias roupas ou um cinto, em uma árvore ou nas vigas de sustentação de suas casas.

\section{MODOS AFIRMATIVOS NO SUICÍDIO KAIOWÁ?}

O suicídio Kaiowá foi retratado com grande espanto na mídia brasileira e internacional principalmente no decorrer da década de 1990, conforme relata Pimentel (2006) devido ao grande aumento de casos anuais. Os relatos midiáticos sobre o tema tomam maior proporção no Brasil e no Paraguai, que colocavam sobre o mesmo plano relatos das autoridades representantes do poder político, de antropólogos, psicólogos e das lideranças indígenas.

Reunindo um vasto número de explicações sobre o tema que variam do alcoolismo à falta de terra, à perda das tradições e presença das missões evangélicas dentre outros, contudo muitas destas narrativas ficam no campo da especulação e da propagação de informações muitas vezes infundadas.

Costa Pereira (apud Pimentel 2006; p.65) é um dos primeiros a fazer um estudo sistemático sobre as principais explicações que são apontadas para se entender 
o fenômeno do suicídio entre os Kaiowá. Apontando uma série de fatores, os mais citados como causa para o fenômeno entre este grupo, habitantes de Dourados, sendo os mais recorrentes: o feitiço e bebida alcoólica, seguidos pela situação econômica precária, conflito de lideranças com poucos poderes entre si, as constantes brigas familiares, o número crescente de pessoas que buscavam os trabalhos nas fazendas, a proliferação dos grupos evangélicos que geram cisão e confrontamento com a tradição e as crenças religiosas e a precária assistência dos órgãos políticos.

Contudo, o autor ressalta que o ato de "feitiço", o pajé vai, é a explicação que se sobrepõe às outras, devido às tênues diferenciações de quem comete um assassinato com as próprias mãos e a feitiçaria.

Levcovitz (1999) propõe uma visão sobre a feitiçaria, o pajé vai, que busca em um passado imemorial o complexo do guerreiro antropofágico tupi-guarani e do ethos minimalista que fora proposto por E. Viveiros de Castro (1986 apud Levcovitz, 200, p. 127). Segundo essa perspectiva existe uma construção da pessoa tupi-guarani de que não se pode abrir mão, e que coloca no centro o "tornar-se outro" Assim, por exemplo, para o guerreiro antropofágico, que buscava a morte através da guerra de vingança, tendo como manifestação de glória ou morrer como guerreiro ou ser capturado e depois ser comido pelo inimigo. Portanto, nestes grupos, a presença do inimigo representado no outro é um elemento estruturante.

Continuando em seu argumento, Levcovitz (1999), sustenta que o suicídio é entendido pelos próprios Kaiowá, como um feitiço, realizado por um inimigo, e ganha, nestes termos, significado social:

O mais essencial, a nosso ver, não está nas características intrínsecas do fenômeno auto agressivo, mas em sua natureza social. O fenômeno individual do suicídio sempre vivenciado pelos índios e seu grupo familiar como um mal produzido por inimigos, um estado de transe que conduz a morte involuntária, produz o estado coletivo estruturalmente relacionado a guerra de vingança. (LEVCOVITZ, 1999; p. 228)

Na interpretação do autor, não encontrando mais o outro como contrário e "parceiro-adversário", o suicida ele mesmo se apresenta neste outro, acometendo contra si mesmo e não tendo, desta forma, que suportar o peso da terra.

Comentando sobre o feitiço existente entre o povo Guarani Kaiowá, Brand 
(1997) demonstra a importância deste elemento na forma de compreensão indígena sobre o suicídio, que é representado nos aty guasu (reuniões das lideranças indígenas) que ele acompanhou. Contudo este reitera não acreditar que esta característica seja dada por um ethos guarani conforme foi tratado por Levcovitz (1999), mas sim que o crescimento da morte auto infligida pelo feitiço reflete uma desintegração cultural que existe dentro do grupo que atinge a própria construção das identidades, podendo ser avaliado como resultante do atual momento histórico do confinamento de suas terras tradicionais, sendo este o ponto central de argumento deste autor.

Marta Azevedo (1987) possui uma teoria sobre o tema que pode ser interessante para demonstrar como a morte autoprovocada é reconhecida entre os próprios Kaiowá. A autora inicia seu relato demonstrando a sua preocupação inicial com a própria definição do termo suicídio e a carga histórica social que este carrega na tradição ocidental cristã, isto é, representado como um ato último de insensatez e covardia. Segundo ela, entre os Guarani, de forma geral, não existe um termo com o mesmo significado de "suicídio", o que poderia se equiparar seria jejuka (matar-se, assassinar) e juasy'y (enforcar-se).

Segundo a autora o suicídio entre os Kaiowá, é compreendido como uma morte voluntária e pode ser tratada como uma escolha entre outras possíveis dentro de uma ética kaiowá:

A morte voluntária assim entendida não nos aparecerá mais como um consentimento passivo a tentações sociais, mas como uma escolha deliberada de uma solução entre outras, como um gesto ético, referindo a princípios, a valores. Portanto, é a partir da ética Kaiowá que devemos tentar desvendar a verdade ou o sentido do ato, para podermos nos relacionar com os fatos. (AZEVEDO, 1987; p.119).

Seguindo esta orientação, a autora defende que o maior número de mortes voluntárias entre os Kaiowá quase sempre tem o seu pico em uma época em que a pessoa está passando por uma mudança interna individual, o sujeito quer ser reconhecido pelo que foi ou pelo que quer ser, e, neste sentido, ela reitera, a morte voluntária, afirma os valores e fundamenta o teko,"é um apelo para os que ficam, faz refletir (o que realmente) sobre o teko porã, reafirmando-o e recriando-o. Exprime a vida de outro modo, manifesta o apego à vida, não qualquer vida, mas uma determinada maneira de viver".(AZEVEDO, 1987; p. 123). 
Pimentel (2006), por sua vez, propõe uma forma de se pensar sobre o fenômeno da morte voluntária entre os Kaiowá de uma perspectiva diferente, visando. Abarcar tanto o plano do parentesco quanto o cosmológico. Segundo este autor, existe uma relação entre o número crescente de guaxos em comparação com o número de suicídios. Para os Kaiowá, de maneira geral, o guaxo é aquele não que foi criado pelos próprios pais, seja devido ao abandono pelos progenitores ou a morte destes. Todavia cabe ressaltar que o guaxo possui pelo menos um dos genitores vivos.

De acordo com o referido autor, os gêmeos demiurgos Sol e Lua eram guaxos, e foram deixados por Nhande Ru, quando ainda estavam na barriga de Nhandesy, ou seja, o pai ainda estava vivo, mas os abandonara. Lua então fora criada na casa dos pássaros yrutáu e lá ela foi vítima de maus tratos.

Mas há algo mais que define a condição de guaxo além da ausência de um dos genitores. O fator que constitui um guaxo é a condição de ser criado e enxergado pelo grupo como tal. Isso quer dizer que pode ocorrer de alguma criança ou jovem ter e reconhecer os genitores e não possuir nenhuma relação entre eles. Assim sendo, esta pessoa é reconhecida como sendo guaxo e o que nos faz compreender que se trata de uma elaboração social.

Para Pimentel (2006), um dos pilares do ser um Guarani é ter parentes e pertencer a um grupo familiar, o téyi, porque ser humano é possuir parentes, viver e conviver com eles. Já o guaxo é privado deste princípio básico. O grande perigo do guaxo para a ordem pública consiste em seu fraco vínculo de pertencimento a alguma parentela, devido à sua criação ou pelos avós ou por outro núcleo familiar que fora adotado.

Esta condição de guaxo; ou não possuir parentes, neste caso, como defendido pelo autor, não ter um dos pais genitores ou de ter sido adotado, conforme trata Pimentel, fragiliza a condição social do jovem e pode fazê-lo mais vulnerável aos constrangimentos sociais. Essa condição, somada à percepção entre os próprios Guarani da instabilidade emocional que acompanha o jovem através da passagem pela puberdade, pode levá-lo a buscar a morte. Uma maneira radical de expressar sua indignação e discordância em relação ao entorno, sendo a morte a expressão de uma vida de desamparo familiar e social.

\section{CONSIDERAÇÕES FINAIS}

As etnografias sobre os Kaiowá a que tive acesso até o momento apontam 
lugares importantes a se considerar em torno do evento do suicídio. Entre eles destacamos a situação territorial que não permite a muitas famílias Kaiowá mobilidade e efetivação do modo de vida do tekoha, onde se vive "entre parentes".

A questão territorial se encontra no cerne desta discussão, não só pelas disputas políticas que essas geram, mas, sobretudo pela importância que a terra ocupa dentro da cosmologia Kaiowá. O tekoha, mais do que um espaço físico, mais do que a própria aldeia, é o local onde se pode desenvolver o jeito Guarani de ser. Com a restrição dos espaços tradicionais e por consequência do tekoha, a morte voluntária pode se apresentar como um caminho a se seguir.

A terra não é um objeto a ser possuído ou utilizado de forma extrativista, é sim um espaço em que proporciona o viver enquanto humano. Por consequência, implica em ter relaçõescom outroseter uma parentela otéyi.Ocomprometimento histórico à manutenção de redes e práticas de parentesco tem sido apontado como um dos fatores cruciais do atual estado de "violência" vivido pelos grupos kaiowá, incluindo-se aqui o tema do suicídio.

Durante o período do esparramo, que se estendeu durante os anos de 1950 e 1970, o modo de vida tradicional foi profundamente modificado, conforme analisa Brand (2007), neste movimento de dispersão e logo em seguida de um ajuntamento forçado devido ao aldeamento compulsório, as terras tradicionais foram desfeitas e famílias que outrora eram próximas se viram separadas. Com isso, conforme salienta o autor, essas perdas trouxeram consigo a desarticulação da economia, da religião e da sociedade.

Outro aspecto fundamental diz respeito à "construção da pessoa" (Seeger et al, 1979) Kaiowá. Lembramos que os suicídios se concentram entre jovens no momento de passagem à idade adulta. Essa transição é objeto de grande atenção por vários povos ameríndios, como demonstram os rituais de iniciação frequentemente realizados, envolvendo um conjunto de medidas voltadas ao aprendizado para a vida adulta e a transformação corporal da pessoa a ser iniciada. A abordagem dos estados de nhemyrõ e vy'a e'y por Pimentel (2007) apontam a centralidade dos estados emocionais da pessoa no contexto do suicídio.

Segundo este autor, o período conturbado e de transição entre a criança e o adulto, carregado de significados e por consequência de uma carga emocional que deve ser vista com atenção pelos pais e principalmente pela comunidade de forma geral. Como vimos anteriormente, é preciso especialmente cuidar para que não se instalem os estados de nhemyrõ e vy'a éy.

A definição destes estados e a "solução" subsequente do suicídio costumam 
ligar-se ao tema da feitiçaria, que aparece, conforme observaram alguns trabalhos comentados acima, como justificativa ou explicação de casos de suicídio por pessoas kaiowá. Aqui a feitiçaria talvez possa reunir aspectos da pessoa e do parentesco na análise.

Por fim, um terceiro aspecto que etnografias contemporâneas sobre grupos Kaiowá que vivem no Mato Grosso do Sul têm revelado são formas de organização e atuação de jovens Kaiowá, o que apontaria para uma sugestão de abordagem de "juventudes indígenas". Não será possível desenvolver o ponto, mas observo brevemente abaixo como a participação de jovens em algumas instâncias políticas poderiam trazer elementos importantes para serem considerados ao lado daqueles do parentesco e da construção da pessoa.

As explicações sobre os motivos que levam os jovens Kaiowá a se matarem, principalmente a partir da década de 1980, defende Brand (1997), giram em torno, da terra, no processo histórico de confinamento pelo qual eles passaram e não se esquecendo dos argumentos dos próprios Kaiowá, no que se refere ao afastamento de jovens em relação ao modo de ser tradicional, o ñande reko, e a aproximação do modo de ser novo, que é relatado como sendo o modo dos jovens, o tekopyahu, que segundo defende o autor se aproxima do tekovai, ou seja, o modo de ser ruim e diferente do que foi aprendido com os antepassados.

A reafirmação dos antigos valores é de grande relevância quando se trata do restabelecimento dos jovens, conforme defende A. Brand, tratando sobre a forma de recuperação que defendem os próprios kaiowá:

Ao destacar as explicações dos Kaiowá/Guarani sobre as causas que estariam a provocar tão grave problema, em especial o feitiço e a doença, ressalta que ambas remetem para o enfraquecimento do papel social dos caciques, o abandono das práticas da religião tradicional e a própria desintegração das comunidades. A difusão da doença do suicídio acontece porque "nosso sistema mudou", ou seja, a sociedade kaiowá/Guarani, sua economia e sua religião mudaram. (BRAND, 1997, p. 202-203).

Mas, se há um argumento que defende o "modo antigo" e condena a mudança, por outro lado, há um reconhecimento da participação jovem efetiva no cotidiano das decisões políticas e o engajamento social no que toca a sua própria perspectiva de vida em relação à dos seus antepassados.

A participação dos jovens nos aty guasu, reuniões entre lideranças kaiowá 
e Guarani, é cada vez maior. Tonico Benites (2014) em sua tese de doutorado ressalta a importância destas grandes reuniões para afirmar os valores e principalmente pela consolidação das lutas pela recuperação dos seus tekoha, tradicionais.

Nestas reuniões, conforme apresenta Benites (2014, p, 181), "é relevante destacar que o Aty Guasu é composto pelos líderes políticos, os líderes espirituais (Nhande ru e Nhandesy) e seus aprendizes (yvyra'ija), e, sobretudo pelas crianças, mulheres e homens pertencentes às várias famílias indígenas". Tendo como foco, a discussão de saberes, representatividade política e debates sobre problemas coletivos, reunião de convivência, projetos para o futuro e afirmação dos antigos valores, através das danças e rezas.

Conforme relata carta divulgada pela assessoria de comunicação do CIMI (Conselho Indigenista Missionário) sobre a retomada o aty jovem, no mês julho deste ano de 2016, em que ressalta a importância da juventude Kaiowá e Guarani, em oposição ao processo histórico de descaso por parte do Estado em relação à situação vivida por comunidades que são violentadas por ordens de despejo, pela agressão armada e pelo preconceito.

Representante clara de uma forma de luta e que se demarca pela sua repercussão política; o uso da palavra como forma de resistência. Foi através do Rap como forma de manifestação, que alguns grupos da juventude Kaiowá, conseguiram, se munindo deste estilo musical, uma forma de manifestar sua posição mediante ao tekopyahu, modo de ser dos jovens e assim denunciar: a violência, o preconceito e a falta de perspectivas.

Amaro (2014) defende que a apropriação do Rap é responsável não por uma dissolução das práticas culturais tradicionais, mas sim, a solidificação de sentimentos de pertencimento lançando mão de posturas que são externas à própria cultura, através da valorização de aspectos internos. Assim, "temos o exemplo dos jovens kaiowás que estão utilizando do rap para falar de sua própria realidade, de sua 'cultura', de modo reflexivo, mas lançando mão de práticas culturais oriundas de outros contextos" (AMARO, 2014; p. 16).

As perspectivas que aqui apresentei tocam os mais diversos pontos; a questão do acesso à terra e seus conflitos, os ataques diretos que são provocados por feitiços, o paje vai, a condição do guaxo e a falta de parentes, as crises emocionais em passagens no ciclo de vida.

Todavia, reservo este espaço para demonstrar uma ressalva. Onde está o olhar do jovem sobre nas análises sobre o suicídio? A participação nos aty guasu 
e o desenvolvimento de reuniões para a própria juventude demonstram que estes são membros ativos da sociedade Guarani e que, apesar dos confrontos históricos, são os jovens agora que continuarão a luta no futuro.

Ainda que seja fundamental considerar a cosmologia, os aspectos culturais e históricos sociais em grande escala, e também os processos pessoais, parece ser interessante buscar uma abordagem do suicídio entre jovens kaiowá numa escala intermediária, ou seja, aquela da "juventude kaiowá", se assim podemos falar. Neste sentido, seria interessante ouvir o que fala esta juventude, que ganha expressão política e estética, sobre a escolha do suicídio entre eles próprios.

\section{REFERÊNCIAS BIBLIOGRÁFICAS}

<http://ces.ibge.gov.br/pt/noticiascenso?view=noticia\&id=3\&idnoticia=219 $4 \&$ busca=1\&t=censo-2010-populacao-indigena-896-9-mil-tem-305-etniasfala-274> acessado em: 20 de maio de 2016.

<http://pib.socioambiental.org/pt/c/0/1/2/populacao-indigena-no-brasil> acessado em: 16 de junho de 2016.

< h t t p: / / w w w. c i m i. or g. br/sit e/pt br/index. php?system = busca\&qry=aty+guasu $\& x=0 \& y=>$ acessado em 23 de novembro de 2016.

AMARO, Rodrigo. O nhandereko rimado no Rap: indigenização da cultura e reflexividade cultural dentre os jovens kaiowás das aldeias de Jaguapirú e Bororó - Dourados/MS. 29a Reunião Brasileira de Antropologia, Natal/RN, 2014.

AZEVEDO, Marta M."JEJUKA - Suicídio entre os Kaiowá”. Mimeo, 1987.

BENITES, Tonico. Rojeroky hina ha roike jevy tekohape (Rezando e lutando): o movimento histórico dos Aty Guasu dos Ava Kaiowa e dos Ava Guarani pela recuperação de seus tekoha. Dissertação de Mestrado, Rio de Janeiro; UFRJ/ MN/PPGAS, 2014.

BRAND, Antonio J. e VIETTA, Katya. "Análise gráfica das ocorrências de suicídios entre os Kaiowá/Guarani, no MS, entre 1981 e 2000" e "Visões Kaiowá sobre os 
suicídios". Tellus -1 Campo Grande, Ed. UCDB,2001.

O impacto da perda da terra sobre a tradição kaiowá/guarani: os difíceis caminhos da palavra. Tese (Doutorado) - Programa de Pós Graduação em História da Pontifícia Universidade Católica, Porto Alegre. 1997.

CARDOSO, Andrey Moreira et al. Mortality among Guarani Indians in Southeastern and Southern Brazil. Cad. Saúde Pública, Rio de Janeiro, v. 27, supl. 2, p. s222-s236, 2011. Available from <http://www.scielo.br/scielo. php?script=sci_arttext\&pid=S0102-311X2011001400010\&lng=en\&nrm=iso > acessado em 16 junho de 2016.

Conselho Indigenista Missionário/MS, Comissão Pró-Índio/SP \& MPF/PGR $3^{a}$ Região. Conflitos de Direitos sobre as Terras Guarani Kaiowá no Estado de Mato Grosso do Sul. São Paulo, Palas Athena, 2000.

DAL POZ, João. Crônica de uma morte anunciada: do suicídio entre os Sorowaha. Revista de Antropologia, São Paulo, v. 43, n 1, p. 89-144, 2000.

DURKHEIM, Émile. Da divisão do trabalho social; As regras do método sociológico; O suicídio; As formas elementares da vida religiosa. São Paulo: Abril Cultural, 1983. (Os Pensadores).

. O suicídio - Estudo Sociológico. Lisboa, Editorial Presença, 1987 [1897].

ENCONTRO ANUAL DA AMPOCS, 31, 2007. Entre nhemyrõ e vy'ae'y: interpretações sobre os motivos e atitudes dos suicidas Guarani-kaiwa. Universidade de São Paulo.2007.

GIDDENS, Antony. Em defesa da Sociologia . São Paulo: Ed. Unesp, 2001. LEVCOVITZ, Sérgio. Kandire - O Paraíso Terreal. Rio de Janeiro, Espaço e Tempo/Te Corá, 1999.

MELIÁ, Bartolomeu; GRÜNBERG, Friedl \& GRÜNBERG, Georg. Los Pa? Tavyterã - Etnografía Guarani Del Paraguay Contemporâneo. Centro de Estudios Antropológicos da Universidade Católica, Assunção, 1976. 
Morte voluntária entre a juventude Kaiowá, pp. 52 - 74

NIMUENDAJU, Curt; As lendas da criação e destruição do mundo como fundamentos dos Apapocuva-Guarani, Editora da Universidade de São Paulo, 1987.

NOGALES, José Manuel Corpas. Aproximacion social y cultura al fenômeno del suicídio. Comunidades étnicas Amerindias. Disponivel em: http://digibug.ugr.es/ handle/10481/18682\#.VUOJ6vIViko. Acesso em: 17 de junho de 2016.

PIMENTEL, Spensy K. Entre o nhemyrõ e vy'ae'y: interpretações sobre motivos e atitudes dos suicidas guarani-kaiowa. 31 Encontro Anual da ANPOCS, Universidade de São Paulo, 2007.

Sansões e Guaxos: Suicídio guarani e kaiowá - uma proposta de síntese. Dissertação de mestrado, São Paulo, PPGAS-USP, 2006.

Relatório de Gestão 2010 / elaborado pela Coordenação Geral de Planejamento e Avaliação CGPLA/DIREX. Brasília: Ministério da Saúde: Fundação Nacional da Saúde, 2011.

SEEGER, A., DA MATTA, R. \& CASTRO, E. V. de. : "A Construção da Pessoa nas Sociedades Indígenas Brasileiras". Boletim do Museu Nacional. 1979.

THOMAZ DE ALMEIDA, Rubem F. "O Caso Guarani: o que dizem os vivos sobre os que se matam", in RICARDO, Carlos Alberto (ed.). Povos Indígenas do Brasil 1991-1995. São Paulo, ISA, 725-8, 1996. 